\title{
INFLUÊNCIA DE VARIÁVEIS METEREOLÓGICAS NO CRESCIMENTO EM DIÂMETRO E ALTURA DE Schizolobium parahyba var. amazonicum
}

\section{Thelma Shirlen Soares ${ }^{1}$ \\ Edmilson Santos $\mathrm{Cruz}^{2}$}

Resumo: Objetivou-se avaliar o efeito da influência de variáveis meteorológicas no crescimento em diâmetro e em altura de paricá (Schizolobium parahyba var. amazonicum) por meio da análise de correlação de Pearson. Foram empregados dados de parcelas permanentes mensuradas do $6^{\circ}$ ao $10^{\circ}$ ano de idade de um plantio no espaçamento 3 × $3 \mathrm{~m}$ localizado em Alta Floresta, MT. Foram calculados, para o período de crescimento avaliado, os incrementos correntes médios, em diâmetro a 1,30 m de altura do solo (dap) e em altura total, os quais foram correlacionados com as variáveis meteorológicas precipitação (Pp), umidade relativa do ar (UR) e velocidade do vento ( $V V)$. Verificou-se que, à exceção da correlação entre o dap e a velocidade do vento, todas as correlações foram significativas. A UR apresentou correlação negativa tanto para incremento em dap quanto para incremento em altura enquanto a $V v$ apresentou correlação negativa com o incremento em dap. Para as demais variáveis, as correlações foram positivas, apresentando relação diretamente proporcional entre as variáveis meteorológicas e os incrementos em dap e em altura das árvores de paricá.

Palavras-chave: Paricá, correlação, variáveis meteorológicas, crescimento.

\footnotetext{
1 Universidade Federal de Goiás - Regional Jataí, Cx Postal 3, 75801-615, Jataí - GO, thelmasoares@ufg.br.

2 Universidade Federal de Goiás - Regional Jataí, Cx Postal 3, 75801-615, Jataí - GO, edmilsonscruz@gmail.com.
} 